\title{
'Memories are made of this': personal reflections on the creation and maintenance of memorials and mementoes
}

\begin{abstract}
In this article the author draws on personal experiences, amongst them the sudden, unexpected death of her own son, to explore the challenges and benefits of creating memorials and mementoes following a significant death. The article supports existing work which argues for the importance of mementoes in creating meaning, particularly in a culture where death is still largely sequestered from public discourse. The author uses examples from her son's death, combined with the experiences of parents in her research study, exploring professional intervention following sudden, unexpected child death. These examples demonstrate that parents may require extremely pragmatic support, for example advice on how to scatter ashes and whether to establish memorials in perpetuity. The article concludes that the prevailing culture of concealment around death could be challenged by a targeted programme of death education, which includes practical advice on creating enduring memorials and mementoes.
\end{abstract}

Keywords: death education, child death, memorials, memoir, cremation, ashes

\section{'So I left the ashes on the working top and put the kettle on'}

Sitting in my office, during a routine tutorial, Flora a BA first year student, is telling me in a typically considered and understated way about the difficulties she has been experiencing since her father's death three months beforehand. During our first meeting, six months prior to this, Flora, a young woman in her early twenties, had told me that her father had terminal cancer and was living in a hospice not far away. We had talked in some depth about the potential challenges of this for Flora, particularly at the start of a programme of University study which would at times be difficult for her. I had been impressed by her determination and composure, although I remained concerned about the strains on her, not least from her own high standards and the stress that would inevitably be present in commencing a new programme of study at a time when her family life was also conferring such significant pressure. Towards the end of the first term, Flora came to see me once again to tell me that her father had died. His death had as far as possible been a 'good' one (Kellehear, 2007, p61) and Flora was feeling calm and to a large extent resolved. Two tutorials later, and we are in the meeting where Flora is explaining to me some of the complications she has been experiencing. Nicholson (2005) cites several 'rules' following a bereavement, the third of which is 'there will be a fight.' 'Flora's experience chimes with Nicholson's yet Flora is studiously trying to avoid the inevitable 'fight' and thereby carrying much of the family stress on her own shoulders. We talk about this for a while and then gazing out of the window, Flora describes to me in great detail her journey to collect her father's ashes from the crematorium. She had offered to do this and yet despite her calm telling, the experience was obviously distressing for her. Flora explains that the train journey to collect the ashes was the same as the one she had made to visit her father in the hospice and portrays movingly, her consequent sense of emotional confusion, when rather than seeing her father she is left transporting what is left of him, inside a pot within a carrier bag. When she arrives home, she tells me, there is no sense of ceremony and she has the stark experience of closing the door and simply having no guidance for where to put the ashes that she has so carefully transported 
home. She laughs for a moment and tells me 'so I left the ashes on the working top and put the kettle on... I didn't really know what else I was supposed to do. ' Support, Flora explains, arrived from the most unlikely of places, when later she turns on a popular TV soap opera and one of the characters is experiencing a very similar situation, which causes Flora to feel less isolated. Flora's account is very familiar to me, from both personal and professional experiences of involvement with death. My doctoral research work (Turner, 2014) focuses on parents' experience of professional intervention following sudden, unexpected child death and I have also faced a number of significant personal deaths, whilst my previous role as a social worker brought me into professional contact with people experiencing both loss and death. Additionally, my present position as a social work academic, involves me in a tutorial capacity with students, many of whom are experiencing death, often for the first time, either within their personal lives, or during placement experiences. Within this article, I draw on these personal and professional experiences to discuss the therapeutic benefits of creating memorial sites and mementoes as part of meaning making following death, but argue further that their creation should be informed by discussion and education as part of ongoing bereavement support and a more open approach to talking about death (Lakhani, 2014).

\section{Making memories}

It is widely acknowledged that memory work is vitally important within bereavement processes. In work with children, finding a means to talk about the dead person has been shown to promote resilience and help them cope with both the death itself and its potential effects on the family (Denis and Makiwane, 2003). An anonymous article (Guardian, 2014) written by a young student, confirms the significance of finding both the space and the means to discuss death. Within the piece the writer explains the effects of not talking about or acknowledging the death of her father, when, like Flora she had only recently started at University. She describes her fear of being labelled as the girl whose father had just died and consequently her quiet internal implosion, whilst no one around her at University noticed. The piece acknowledges that her experience was made significantly worse by the lack of support she was able to access and her own

fears of being labelled, which prevented her from undertaking important emotional work around her father's death. Lakhani (2014) writing in the Guardian suggests that this death avoidance is almost endemic in Britain. Research cited in Lakhani's article and especially commissioned for Dying Matters Awareness Week 2014, found that $83 \%$ of the British public believe it is too difficult to discuss death, whilst $51 \%$ of those with a partner have never discussed end of life wishes. Lakhani, a GP, suggests that proper planning and provision of options can play a key role in support around death and much of this good practice will include funeral sites, arrangements for the scattering of ashes and other enduring memorial considerations. As I have described, my own interest in memory work is rooted in both professional and personal experience. I have encountered death both within differing personal and professional capacities however, my most significant experience of memory work is drawn from events which followed the death of my son, Joe, in 2005. Born nearly two months premature, weighing only three pounds and 11 ounces, Joe was the eldest by a minute of twin boys, delivered by emergency Caesarean section, during the hottest summer ever recorded th that time. His prematurity led to Joe experiencing a succession of physical threats following his birth, including suspected brain damage, deafness and a virulent digestive condition. However, Joe was able to overcome all of these and six weeks after his birth, alongside his twin brother, and his proud big sister, then aged four, he left hospital for home. Joe grew into a robust and cheerful toddler, who by 19 months could walk and say quite a few words. There seemed little physical legacy from the complications that he had endured at birth and he passed his first years health check with negligible concern. His death then, suddenly and unexpectedly, one night during 2005 , was a devastating and 
unpredicted event, which eventually led to my doctoral research (Turner, 2014) but in the short term, left us as a family both in shock and like Flora, lacking in practical advice. Riches and Dawson $(2000, p 77)$ in a study of bereaved children, report that 'the key message we hear over and over again is that bereaved siblings feel they are overlooked. ' At the time of Joe's death, my professional experience rendered me aware of this and consequently I was determined that neither of my two surviving children, should suffer in this way. My son, was like Joe only 19 months, but my daughter was by now aged six and in her second year at primary school. Whilst my surviving son, perhaps surprisingly, did not show any immediate reactions to Joe's death, my daughter refused to have any of Joe's personal effects, including photographs of him visible within our home. Instead she requested, quite calmly that all traces of Joe be placed inside a box. It was as if in her mind, Joe was no longer there and therefore should be tidied away. I instinctively followed her wishes, accompanying her to a local store where she chose a hinged wooden box. Returning home, we filled it with Joe's things including his birth certificate, his first shoes, favourite toys and photographs. My daughter suggested that we draw messages and pictures to paste onto the box, which she then decorated. Unwittingly, through following my daughter's wishes, we had created a memory box with each of us, children and adult alike, taking an active part in its creation. Research involving children orphaned by Aids (Denis and Makiwane, 2003) illustrates how participation in this family event may reduce the risk of isolation to children, following bereavement. Additionally, with young children and even with older people, involvement in creating mementos where writing does not form the focus can be particularly beneficial (Thomson and Holland, 2005). Following the creation of the memory box and in the immediate aftermath of Joe's death, my daughter had two days away from school. However, she was not unduly distressed and it seemed sensible to return her before her routine became additionally disrupted. On her first day back, she proudly asked to take the box with her, a request which immediately filled me with dread. Adhering to my principal that she should not feel overlooked, we duly carried the box into school with us, initially keeping an appointment with the Headteacher. This woman, lacking any specialist bereavement training, had already instinctively acted in a very supportive way around the circumstances of Joe's death. On the morning of my daughter's return to school, apparently un-phased by the large wooden box in her office, she calmly suggested that I leave and that she take my daughter and the box into class, where she could explain to the children what had happened to Joe. Although my anxiety at the time made it difficult for me to relinquish control, I recognised the sense in what the Headteacher was saying and left her, with my daughter, to show a class of Year One primary school children the contents of Joe's box, including his shoes, his toothbrush and his favourite toys. That day they kept the box in the school library and my daughter was allowed to visit it as often as she wanted, taking a friend with her. At the end of the day she was told that she could keep the box in the library if she wanted to but she said it was all right to take it home. I felt that the box had done what it needed to do. My daughter had brought her dead brother to school and made him and the events of his death real, supported by the instinctive strength and humanity of her Headteacher. My daughter's experience at school is confirmed by the limited research on memory boxes. Denis and Makiwane $(2003, \mathrm{p} 66)$ found that the initial construction of a memory box, followed by the sharing of the contents can act as an instigator for breaking the silence around death and thus help the 'unknown become a little less unfamiliar.' Dent and Stewart (2004) endorse this, suggesting that given the important role of educational institutions in children's lives, resources are needed that support children when a significant death occurs. Cook-Cottone and Beck (2007) also propose the construction of a life box, book or other form of aid for sharing with school friends and although research is very limited, my daughter's impromptu creation of a memory box and her subsequent experience at school seems to support this. 
Research has shown that the death of her sibling may have a profound effect on the self-identity of surviving children with the possible consequences extending into adult life (Dent and Stewart, 2004). Methods may therefore be needed which help to bridge the potential chaos and threats to identity that loss and death may bring (Dent and Stewart, 2004). In a study of young people's transition to adulthood, Thomson and Holland, (2005, p202) placed their participants at the 'core of the construction of their own identity' which echoes my daughter's lead in creating Joe's memory box. My own research work (Turner, 2014) which focusses on parents experience of professional intervention following sudden, unexpected child death found that contemporary good practice guidelines encourage practitioners to offer parents support in creating mementos, including handprints and locks of hair (Dent and Stewart, 2004; Sidebotham and Fleming, 2007). However, practitioners are offered little support with the practicalities of this and parents may often perceive their interventions as clumsy and lacking in empathy (Turner, 2014). Professionals themselves also report feeling 'hugely ill-prepared', discomfited and distressed, with a 'general lack of confidence' when asked to intervene in this area (Dent and Stewart, 2004, p110). Lakhani's article (Guardian, 2014) supports this suggesting that Doctors are failing to talk about dying, which can almost be viewed as an insult to their healing vocation. Within my research, parents frequently explained their need for extremely pragmatic support, following the deaths of their children. Much of this support centred around practical processes like arranging the funeral, explaining death to surviving children and making decisions around how to dispose of ashes (Turner, 2014). Several parents reported their frustration with the lack of information, hushed tones and referrals to counselling, where what they required was often practical signposting to help them make informed choices. Like Flora, disposal of the ashes was something which many parents highlighted as an area of potential difficulty, at a very sensitive time. Laurie, whose son George died suddenly and unexpectedly, aged two, highlights this dilemma movingly, in her description of negotiating with both her husband, Mike and her surviving son, Josh:

After the funeral we had to think about scattering the ashes...I had previously explained to [Josh] that at a crematorium there's a machine called a furnace and the job of the machine is to make bodies into dust and we had left it at that for a long time. Then one evening just before bed, Josh asked his Dad, 'What happened to George's dust?' We then explained that at some point we would pick special places, although Mike and I hadn't actually discussed it as a couple, we'd just kind of loosely talked about it. When Mike and Josh got talking about it that made it more accessible and more real and so Mike told Josh that we would pick special places and we'll scatter George's ashes in those special places that mean a lot to us. Even before Mike asked if he would like to choose somewhere, Josh said that he knew a really good place. He remembered a boat trip we taken on a previous summer holiday and how much George had loved it there. The phrase out of the mouths of babes seems so appropriate to me, because children have led me through my grief. Not just Josh but all his little friends. I've seen numerous parents squirming at the voices of their children... But children's grief can teach adults a heck of a lot of stuff because adults pussyfoot around it all shockingly... So the scattering of the ashes was very important and we still have some and we haven't chosen the last place yet. We've picked three places individually and three very different places. From speaking to other people I understand that some people keep their ashes in the cupboard for years, which is absolutely fine if that's what's right for them but it's not for us (Turner, 2014, p295).

Laurie and her family, as this extract powerfully demonstrates, were able to negotiate the scattering of George's ashes, through following the lead of their surviving son and their abiding determination to ensure that he does not become a 'forgotten mourner' (Hindmarch, 1995 p37) living amidst the grief of his parents (Dent and Stewart, 2004) which echoes my experience of creating Joe's box. 
However, for those families who as Laurie describes 'keep their ashes in the cupboard for years' this is not necessarily because it is 'what is right for them', but often the result of a lack of support and emotional energy. My own experience of Joe's ashes reflects this. When Joe died, his body immediately became the property of the coroner and he was taken to London for a paediatric post mortem to be finally released three weeks later, after a cause of death had been ascertained. We were then able to hold a funeral, and decided on a cremation as we did not wish to have a grave to visit in perpetuity, a decision reflected by other parents in my research study (Turner, 2014). The reverberations from Joe's death and my determination to safeguard the welfare of my two surviving children left me with more than enough to occupy my time in the weeks and months after the funeral. It was only when I began my doctoral research and progressed to fieldwork, that hearing stories like Laurie's, about disposal of the ashes, I realised with a mixture of surprise and horror that we had never received Joe's ashes, or indeed had any information about these. By this time, however, it was several years after his death and although I initially felt agitated that I had never received the ashes, I finally realised it was almost a relief - yet another traumatic emotional and practical decision had somehow been lifted from my shoulders and I came to terms surprisingly easily with what had happened. It was with some surprise then, that in the summer of 2013, nearly nine years after Joe's death and ironically just as I was completing the doctoral research prompted by this, I received a phone call from the undertaker. Without acknowledging the nine years that stretched between us, the undertaker's secretary asked me, as if the death had only been yesterday, what I would like to do with the ashes. I pictured myself, like Flora, with the ashes

in a carrier bag on my working top, nearly a decade after Joe had died. Patiently, the woman on the other end of the phone explained to me that if I did not come and collect the ashes, they would dispose of them themselves, a choice which in that moment felt almost literally paralysing. The telephone call and disturbing reintroduction of Joe's ashes into my life, propelled me backwards, to the creation of his memory box and other memorials at the time of his death, which in the nine intervening years, had lost their immediate therapeutic sheen and acquired an enduring 'material presence' (Thomson and Holland, 2005, p217) which was both troubling and at times disruptive to our continuing lives.

\section{Making room for the present}

In the novel Brideshead Revisited (Waugh, 1945) the narrator Charles Ryder suggests that the past and future sometimes impose themselves upon him so heavily that they leave no room for the present, a statement which resonates both with my personal experience and that of many of the parents within my research (Turner, 2014). Normalising theories about bereavement processes (Speedy, 2008) suggests that those bereaved by the death of someone close, may never really feel all right again, nor come to terms with and even move on from the death (Dent and Stewart, 2004). However, my research supports that of contemporary theorists like Neimeyer (2000) who identify meaning making as one of the key factors for successful integration of death into a continuing life story. This making of meaning may often be wrought from decisions made at the time of death with respect to ashes, grave sites, rituals and memorial artefacts which help to create a sense of continuity during a period of fracture. My experience and that of parents in my study suggests that support with making these decisions, in the knowledge that they will continue to affect the future could be vital in influencing people's ability to integrate death into ongoing lives. In their study of young people and memory books, Thomson and Holland $(2005$, p217) state 'we have been particularly exercised by their material presence' which echoes my own experience, both with Joe's memory box and a memorial bench, purchased shortly after his death. The latter was acquired with money collected by people attending two local playgroups I had regularly visited with my twin boys. 
The collection, made in response to Joe's death, was very moving and it seemed right to me at the time, that we use it for something substantive which would secure Joe's memory. Accordingly, we bought a bench in a local park and it was inscribed with Joe's name, the names of his siblings, then aged 19 months and six respectively, and Joe's dates of birth and death. A year after his death, we held a ceremony at the bench and released helium balloons. As the years passed however, the ritual we had established at this time, began to weigh heavily on both me and my children. As my son and daughter grew older, the immediate connection to Joe inevitably became more tenuous and yet we dutifully marched down to the bench every year on the anniversary of his death. Towards the close of my son's first year at primary school, his class made a special trip to this local park, to study the signs of spring and I accompanied them, together with other parent helpers. It was with a rising tide of anxiety, that I realised we would be passing the bench, as being three years after Joe's death, my son had established himself as an individual and most people did not know that he had once been a twin. As we passed the bench, I could see parents and those children able to read, scanning the inscription. To my horror, one child, with whom my son had a poor relationship, began to tease him about the inscription, following this by sitting on the bench. My son reacted badly, lashing out at the child, insisting that he move away from his brother's bench. Some of the parents began to quiz me about the bench, asking if my son had indeed been a twin and commenting on the experience, whilst I made feeble attempts to maintain some kind of social veneer. In their research with memory books, Thomson and Holland (2005, p217) cite the 'voyeurism' and 'prurient fascination' which can arise when memorials enter the public domain. I had experienced some of this prurience at time of Joe's death, but this episode in the park was one of my first encounters with the disconcerting material presence that such memorials may continue to exercise, years after their initial establishment appeared as a good idea. Nine years after Joe's death, I finally decided not to make the annual pilgrimage down to the bench on the anniversary of his death. It was no longer a celebration, but felt more like a compulsion brought on by guilt and simply not knowing how to appropriately end the ritual. Similarly, whilst the creation of Joe's box was undoubtedly positive and therapeutic at the time of his death, my continuing relationship with it has become uneasy. Thomson and Holland suggest quite rightly that memory boxes form an 'enduring record of bodies at particular moments' (2005, p213) and whilst this may be beneficial in the immediate aftermath of a death, there is little research or information about how to integrate the permanence of this artefact into a dynamic and changing life. When I am faced with Joe's box now, it appears as an uncomfortable record, both of his death and the events which followed this - under its wooden lid, decorated with childish pictures, are his toothbrush, his favourite toy and his first shoes. Raising this lid, like Pandora's box, releases painful memories of a bygone world, which nevertheless remains permanently captured therein. With hindsight, I would have liked perhaps to add something to the box every year, until this too felt no longer necessary, or at least to have discussed the potential of the enduring presence of Joe's box at the time of its creation.

\section{Life after death}

Lakhani (2014) advocates powerfully for the need to break down taboos around dying and begin to discuss it openly, which is strongly supported by findings in my research (Turner, 2014). However, whilst Lakhani's argument focusses predominantly on

conversations around end of life care, my own personal experience and that of parents in my study, together with students like Flora, demonstrate a need for conversations which also concentrate on the enduring material presence of decisions made at that time. If I had considered the establishment of a bench as a permanent memorial to Joe more carefully, I would not necessarily have made a different decision, but I might have been more fully prepared for its continuing manifestation in my 
life. Similarly, the rituals created at the time of death will often inevitably reach a natural end, and support with the guilt created in moving on from these could form part of both initial and ongoing bereavement support. Creating meaning from death is one of the key tasks in integration (Neimeyer, 2000) and this meaning can often be achieved by the production of physical spaces or artefacts such as burial sites, locks of hair, memory boxes, trees or benches. Informed education about the potential long term emotional consequences of maintaining, or further failing to maintain these sites would be enormously beneficial as a part of the talking about death which Lakhani so rightly promotes. 圆

Anonymous (Blogging student) (2014). My father died when I started university and I didn't tell anyone. The Guardian. Available from:

http://www.theguardian.com/education/mortarboard/2014/apr/11/ university-students-dealingwith-death [Accessed 30 June 2014].

Cook-Cottone C, Beck M (2007). A model for life-story work: facilitating the construction of personal narrative for foster children. Child and Adolescent Mental Health 12(4) 193-195.

Denis P, Makiwane N (2003). Stories of love, pain and courage: Aids orphans and memory boxes. Oral History 31(2) 66-74.

Dent A, Stewart A (2004). Sudden death in childhood. London: Butterworth-Heinemann.

Hindmarch C (1995). Secondary losses for siblings. Child: Care Health and Development 21 425-431. Kellehear A (2007). A social history of dying.

In Earle S, Komaromy C, Batholemew C, Death and dying, a reader. Milton Keynes: Open University 61-84

Lakhani M (2014). Why we need to have a national conversation about dying. The Guardian online. Available from: http://www. theguardian.com/healthcare-network/2014/may/13/neednationalconversation-dying?CMP=twt_gu [Accessed 30 June 2014].

Neimeyer R (2000). Searching for meaning of meaning: grief therapy and process of reconstruction. Death Studies 24(6) 541-558.

Neimeyer RA (1999). Narrative strategies in grief therapy. Journal of Constructivist Psychology 12(1) 65-85. Nicholson L (2005). Living on the seabed. London: Random House.

Riches G, Dawson P (2000) An intimate loneliness: supporting bereaved parents and siblings. Milton Keynes: Open University Press.

Sidebotham S, Fleming P (2007). Unexpected death in childhood: a handbook for practitioners. London: John Wiley \& Sons.

Speedy J (2008). Narrative inquiry and psychotherapy. London: Palgrave MacMillan.

Thomson R, Holland J (2005). Thanks for the memory: memory books as a methodological resource in biographical research. Qualitative Research 5(2) 201-216.

Turner D (2014). Telling the story: what can be learned from parent's experience of the professional response following the sudden, unexpected death of a child. PhD Thesis. University of Sussex, UK.

Waugh E (1945). Brideshead revisited. UK: Penguin Books. 